\title{
Food Safety on the Farm: Good Agricultural Practices and Good Handling Practices-Sanitary Facilities ${ }^{1}$
}

\author{
J. A. Lepper, R. M. Goodrich-Schneider, A. Sreedharan, and K. R. Schneider ${ }^{2}$
}

As part of the Food Safety on the Farm series, a collection that reviews the generally recognized principles of GAPs as they relate to produce, primarily at the farm level and with particular focus on fresh Florida crops and practices, this publication focuses on GAPs and GHPs relating specifically to sanitary facilities. The publications in this series can be found online at the EDIS website at http://edis.ifas.ufl.edu/ topic_series_food_safety_on_the_farm.

\section{Introduction}

Good agricultural practices (GAPs) and good handling practices (GHPs) encompass the general procedures that growers, packers, and processors of fresh fruits and vegetables should follow to ensure the safety of their product. GAPs usually deal with preharvest practices (i.e., in the field), while GHPs cover postharvest practices, including packing and shipping. This factsheet covers GAPs relating to sanitary facilities. The seven other UF/IFAS Extension factsheets in the "Food Safety on the Farm" series focus on specific aspects of the GAPs program and how they relate to Florida crops and practices.

Under the new Food Safety Modernization Act (FSMA), GAPs are the foundation of the Produce Safety Rule (PSR). Other than for round tomatoes in Florida (T-GAPs regulation), GAPs have mainly been a voluntary program. Additionally, the PSR mandates that all non-exempt operations follow these new FSMA federal guidelines (Food and
Drug Administration [FDA] 2017a), but GAPs may still be required for exempt commodities and for those producers exporting to foreign countries. Both the mandatory PSR and GAPs aim to reduce the foodborne illness burden associated with produce.

\section{Microbial Hazards}

The term "sanitary facilities" refers to toilets, handwashing stations, and other places where human wastes may be present. Human wastes are known to harbor pathogenic microorganisms that cause disease in workers and consumers of fresh produce. Wastes in the field or packing facility must be managed properly to decrease the risk of contaminating produce.

\section{Regulatory Background}

The federal government regulates standards for field and facility sanitation practices during pre- and postharvest operations of produce. The sanitation provisions in the Occupational Safety and Health Act (OSHA) in the Code of Federal Regulations (CFR) describe requirements for sanitary facilities in agricultural establishments (CFR 2010a). Included are standards for drinking water and toilet and handwashing facilities and their maintenance, such as the maximum distance employees can be expected to walk to facilities and how often facilities should be cleaned.

1. This document is FSHN10-11, one of a series of the Food Science and Human Nutrition Department, UF/IFAS Extension. Original publication date March 2012. Revised November 2017. Visit the EDIS website at http://edis.ifas.ufl.edu.

2. J. A. Lepper, food safety coordinator; R. M. Goodrich-Schneider, professor; A. Sreedharan, former postdoctoral research associate; and K. R. Schneider, professor; Food Science and Human Nutrition Department, UF/IFAS Extension, Gainesville, FL 32611.

The Institute of Food and Agricultural Sciences (IFAS) is an Equal Opportunity Institution authorized to provide research, educational information and other services only to individuals and institutions that function with non-discrimination with respect to race, creed, color, religion, age, disability, sex, sexual orientation, marital status, national origin, political opinions or affiliations. For more information on obtaining other UF/IFAS Extension publications, contact your county's UF/IFAS Extension office. 
Another section of the CFR outlines standards for sanitary facilities in permanent places of employment, such as in an enclosed packing facility (CFR 2010b). The CFR is also a resource for good manufacturing practices (GMPs) required for facilities, equipment, and production of foods in plants or mixed-type facilities (operations that conduct activities both covered and not covered by the farm definition) unless otherwise exempt (CFR 2016). Since the enactment of the FSMA, GMPs have been reorganized and moved from 21 CFR part 110 to 21 CFR part 117. Requirements on water supplies, plumbing, toilet and hand-washing facilities, drainage, and sewage, rubbish, and offal disposal are included (CFR 2016). A farm mixed-type facility that creates a distinct raw agricultural commodity (RAC) processed beyond drying, dehydrating, packaging, and/ or labeling (e.g., dried, diced mangoes) must comply with these regulations unless that facility meets the specifications for an exemption or a qualified exemption. However, if a farm or farm mixed-type facility dries or dehydrates a RAC to create a distinct commodity without further processing (e.g., dried, whole blueberries), that entity can meet FSMA requirements for packing, packaging, and holding activities by either complying with the PSR found in 21 CFR part 112 or by complying with GMPs in subpart B of the Preventive Controls for Human Food (PCHF). Any activities of a farm mixed-type facility that fall within the farm definition are exempt from GMPs and may have to comply with the PSR.

Considering the FSMA regulations are science-based, minimum standards for safe food practices, growers must be aware of, and comply with, more stringent regulations. State and local regulatory authorities can adopt mandatory and more specific regulations to improve food safety. Tomato operations in Florida must follow sanitary facility standards among other Tomato Good Agricultural Practices (T-GAPs) during all steps of production (Florida Department of Agriculture and Consumer Services 2016). Sewage biosolid land application is prohibited for Florida tomato growers due to T-GAPs restrictions despite being allowed for use under the PSR if 40 CFR part 503 is met. These guidelines found in the Tomato Best Practices Manual have been made into rule ( Chapter 5G-6) pursuant to Tomato Inspection Law Section 500.70 of the Florida Statutes, which took effect July 1, 2008 (Florida Administrative Code 2007).

In response to and recognition of growing food safety issues, the FSMA was passed by Congress and signed by the President in January 2011 (FDA 2017a). The new law requires companies to implement a food safety program that significantly minimizes potential hazards and risk of foodborne illness. The PSR, one of the main components of the FSMA, establishes standards to ensure safe growing, harvesting, packing, and holding of covered produce on farms. GAPs programs are currently intended as guidance, not as a regulation (except for Florida T-GAPs), but are usually enforced by the buyers. However, the PSR is required for all non-exempt operations that fall under the farm definition (CFR 2016; FDA 2017b). A coverage and exemptions flow chart is available on the FDA website for operations to help determine compliance with the PSR (FDA 2015). In the PSR, Subpart L (Equipment, Tools, Buildings, and Sanitation) requires businesses to ensure that buildings/operations must provide accessible toilet and hand washable facilities (FDA 2017b). Furthermore, Subparts C and D of the PSR (Personnel Qualifications and Training and Health and Hygiene, respectively) also require companies to provide proper toilet and hand-washing facilities to visitors to protect produce and food-contact surfaces from contamination (FDA 2017b). All visitors and personnel must be trained on the operation's food safety and hygiene policies while recording the date, name of person trained, and the specific topics covered (FDA 2017b). Whether covered or exempt, taking immediate steps to implement sanitation facility GAPs will benefit a company's financial viability and overall produce safety. Morever, even farms exempt from the PSR are subject to the provisions of the Food, Drug and Cosmetic Act (FD\&C Act) that prevent adulterated food from entering commerce.

\section{How to Control Potential Hazards}

For FSMA regulations such as the PSR to be successful, prerequisite programs such as GAPs are necessary to bolster such broad, scalable provisions. Required regulations like the PSR use mandatory verbiage, such as "must", as opposed to suggested verbiage used in GAPs, such as "should." Guidance from GAPs may be used to satisfy a mandatory requirement in the PSR and play an imperative role in the reduction of potential hazards. Implementing and maintaining sanitation standards protects employees and consumers from foodborne disease and lowers the risk of contaminating fresh produce. The following GAPs in toilet and handwashing facilities and sewage disposal have been highlighted by the US Food and Drug Administration (FDA) (FDA 1998).

\section{Toilet Facilities and Handwashing Stations}

The following GAPs should be considered to ensure that toilet and handwashing facilities are in good sanitary condition. 
- Toilet facilities (both fixed and/or portable) should be accessible. Facilities must be reasonably near employees' work areas and available at all times, not only when workers are on break. Accessible facilities help lower the chance that workers will relieve themselves in undesignated areas, such as in fields, and thereby risk contamination of produce.

- Toilet facilities should be properly located. To prevent possible contamination of fields, soil, and animals, toilet facilities should be properly constructed and located in areas where there is little potential for runoff in the event of heavy rain. Facilities should also be located away from sources of irrigation water.

- Toilet facilities and handwashing stations should be well supplied. Toilet facilities should be well supplied with toilet paper. Handwashing facilities should provide a basin, potable water, liquid soap, single-use towels, and a waste container. Wash water should be captured for proper disposal.

- All facilities should be kept clean. Facilities must be operational, adequately ventilated, and cleaned regularly. Handwashing basins or containers used to store or transport water must be emptied, cleaned, and sanitized regularly.

\section{Sewage Disposal}

Human wastes from toilets must be managed safely and disposed of properly to prevent drainage into fields and possible contamination of water, soil, animals, crops, and workers. Refer to the regulations by the US Environmental Protection Agency (EPA) in the CFR for the use and disposal of sewage (CFR 2010c). Consider the following GAPs when establishing sewage disposal practices:

- Use caution when servicing portable toilets. Allow sewage transport trucks direct access to toilet facilities to ensure proper collection and disposal of wastes.

- Have a plan to contain and treat spills and leaks. Be prepared for the event of a spill or leak into produce fields.

\section{References}

Code of Federal Regulations. 2010a. "Occupational Safety and Health Standards for Agriculture: Field Sanitation." Title 29, Part 1928.110. Washington, D.C.: U.S. Food and Drug Administration, Office of the Federal Register. Accessed Aug 4, 2017. https://www.ecfr.gov/cgi-bin/text idx ?SID=6fc9c70e4e6f783fb0ca610dbed21468\&mc=true\&nod $\mathrm{e}=$ se29.9.1928_1110\&rgn=div8.
Code of Federal Regulations. 2010b. "Occupational Health and Safety Standards: Sanitation.” Title 29, Part 1910.141, subpart J. Washington, D.C.: U.S. Food and Drug Administration, Office of the Federal Register. Accessed Aug 4, 2017. https://www.gpo.gov/fdsys/pkg/CFR-2001-title29vol5/pdf/CFR-2001-title29-vol5-part1910-subpartJ.pdf.

Code of Federal Regulations. 2010c. "Standards for the Use or Disposal of Sewage Sludge. Title 40, Part 503.” Washington, D.C.: U.S. Food and Drug Administration, Office of the Federal Register. Accessed Aug 4, 2017. https://www.ecfr.gov/cgi-bin/text-idx?tpl=/ecfrbrowse/ Title40/40cfr503_main_02.tpl.

Code of Federal Regulations. 2016. "Current Good Manufacturing Practice, Hazard Analysis, and Risk-Based Preventive Controls for Human Food." Title 21, Part 117. Washington, D.C.: U.S. Food and Drug Administration, Office of the Federal Register. Accessed Aug 4, 2017. https://www.accessdata.fda.gov/scripts/cdrh/cfdocs/cfcfr/ CFRSearch.cfm?CFRPart=117.

Florida Administrative Code. 2007. "Rule 5G-6. Tomato inspection.” Accessed Nov 07, 2017. https://www.flrules. org/gateway/ChapterHome.asp?Chapter=5G-6.

Florida Department of Agriculture and Consumer Services. 2014. "Rule 5G-6. Tomato Best Practices Manual." Accessed Nov 07, 2017. http://fvreports.freshfromflorida. com/5G_TomBPM.pdf.

Food and Drug Administration. 1998. "Guide to Minimize Microbial Food Safety Hazards for Fresh Fruits and Vegetables." Washington, D.C.: U.S. Department of Health and Human Services, FDA. Accessed June 9, 2017. http://www. fda.gov/downloads/Food/GuidanceComplianceRegulatoryInformation/GuidanceDocuments/ProduceandPlanProducts/UCM169112.pdf.

Food and Drug Administration. 2015. "Standards for Produce Safety Coverage and Exemptions/Exclusions for 21 Part 112." Accessed June 9, 2017. https://www. fda.gov/downloads/Food/GuidanceRegulation/FSMA/ UCM472499.pdf.

Food and Drug Administration. 2017a. "FDA Food Safety Modernization Act." Accessed June 09, 2017. http://www. fda.gov/Food/GuidanceRegulation/FSMA/default.htm.

Food and Drug Administration. 2017b. "FSMA Final Rule on Produce Safety." Accessed June 9, 2017. http://www.fda. gov/Food/GuidanceRegulation/FSMA/ucm334114.htm. 